\title{
Annealing of Thin “Tincone" Films, a Tin-based Hybrid Material deposited by Molecular Layer Deposition, in Reducing, Inert and Oxidizing Atmospheres
}

\author{
Kevin Van de Kerckhove, ${ }^{*}$ Jolien Dendooven, and Christophe Detavernier \\ Department of Solid State Sciences, Ghent University, Krijgslaan 281 S1, 9000 Ghent, Belgium \\ E-mail: kevin.vandekerckhove@ugent.be
}

\begin{abstract}
Molecular layer deposition (MLD) of hybrid organic-inorganic thin films called "tincones" is achieved using tetrakisdimethylaminotin (TDMASn) as the metal precursor, and glycerol (GL) as the organic reactant. The GL-based process displays linear growth and self-limiting surface reactions in a broad temperature window ranging from $75^{\circ} \mathrm{C}$ to $200^{\circ} \mathrm{C}$. At higher temperatures no film growth is possible. The GPC decreases rapidly with increasing temperature from $1.3 \AA$ at $75^{\circ} \mathrm{C}$ to less than $0.1 \AA$ at $200{ }^{\circ} \mathrm{C}$. The films are observed to be smooth with scanning electron microscopy (SEM) and atomic force microscopy (AFM). The hybrid organic-inorganic nature of the films is visible in both infrared spectroscopy (FTIR) and X-ray photoelectron spectroscopy (XPS). As deposited tincone films are annealed in reducing $\left(\mathrm{H}_{2}\right)$, inert $(\mathrm{He})$ or oxidizing $\left(\mathrm{O}_{2}\right)$ atmospheres. In situ X-ray diffraction (XRD) is employed to study the crystallization of the films during annealing. Tincone films annealed in reducing or inert atmosphere crystallize into a tetragonal $\mathrm{SnO}$ phase at $388^{\circ} \mathrm{C}$ and $410^{\circ} \mathrm{C}$ respectively. These temperatures are lower than the crystallization temperature of $480^{\circ} \mathrm{C}$ for ALD tin oxide films annealed in $\mathrm{H}_{2}$. Tincone films annealed in oxygen crystallize into a $\mathrm{SnO}_{2}$ phase at a temperature of $523^{\circ} \mathrm{C}$ which is similar to the crystallization temperature for ALD tin oxide films annealed in $\mathrm{He}$ or $\mathrm{O}_{2}$. This reduced temperature for crystallization into $\mathrm{SnO}$ for the tincone films is interesting since $\mathrm{SnO}$ is one of the few metal oxides known as a p-type semiconductor material.
\end{abstract}




\section{Introduction}

The current trend towards miniaturization of electronic devices and components is a driving force for research into the deposition and properties of thin films. One thin-film deposition technique that has gained a significant amount of traction in recent years is atomic layer deposition (ALD). The ALD technique allows the controlled deposition of nanoscale films of a wide variety of materials (including metals, metal oxides, sulfides, etc.) through sequential exposure of the substrate to a precursor and reactant. ${ }^{1}$ The self-limiting nature of the gassurface reactions allow for sub-nanometer thickness control and great conformality on 3D structures.

Molecular layer deposition (MLD) is a thin-film deposition technique closely related to ALD. It is employed for the deposition of purely organic or hybrid organicinorganic films. The latter is accomplished by combining metal-organic precursors, that are usually well-known from ALD research, with organic reactants such as ethylene glycol (EG) and glycerol (GL). The hybrid films that are deposited by this technique are commonly referred to as "metalcones". An extensive catalog of hybrid materials has already been established in the literature: alucone, titanicone, zincone, zircone, hafnicone, vanadicone, and more. ${ }^{2-11}$ To the extent of our knowledge, no MLD process for a tin-based metalcone has been reported yet. Metalcones have been shown to possess several interesting properties in the literature. The organic chains present in the hybrid films add flexibility to the films, which is interesting for applications in flexible electronics and thin-film electrodes. ${ }^{12,13}$ Post-deposition treatments are known to transform the metalcone films. Calcination in air and water etching are able to induce porosity in alucone films. ${ }^{4,14,15}$ Annealing of metalcone films in inert atmosphere leads to a metal oxide/carbon composite film with improved conductivity. ${ }^{6,11,16,17}$

Tin oxides have a wide variety of technological applications. As a semiconductor with a large band-gap, tin dioxide $\left(\mathrm{SnO}_{2}\right)$ is a promising material for solid state gas sensors. ${ }^{18-20}$ In optical applications, tin oxides are utilized as a transparent conducting oxide in organic lightemitting diodes (OLED) $)^{21,22}$ and solar cells ${ }^{23,24}$, and as surface coatings for functional glasses, due to their reflectance in the infrared. ${ }^{25}$ Tin dioxide is also an interesting, high-capacity, anodic material for lithium-ion batteries. ${ }^{26-28}$ Tin monoxide $(\mathrm{SnO})$ is one of the few known p-type semiconductor materials and is hence interesting for electronic applications such as the fabrication of $p-n$ junctions and complementary metal oxide semiconductor (CMOS) architectures. ${ }^{29,30}$

Many ALD processes are known in the literature for the deposition of tin oxide films. $\mathrm{SnCl}_{4}, \mathrm{SnI}_{4}$ and tetrakisdimethylaminotin (TDMASn) are a few common examples of the Sn metal precursors that are employed in these processes in combination with water, $\mathrm{H}_{2} \mathrm{O}_{2}, \mathrm{O}_{3}$ or oxygen plasma as the reactant. A nice and thorough overview of tin oxide ALD processes has been written down by Nazorov et al. ${ }^{31}$

In this work, two MLD processes for a novel metalcone material tincone were investigated. Both processes employ TDMASn as the tin precursor and ethylene glycol or glycerol as the organic reactant. The growth of the tincone films was monitored in situ during the process. The properties of the grown tincone films were characterized with various ex situ methods. A series of as deposited films was subjected to an annealing treatment in reducing $\left(\mathrm{H}_{2}\right)$, inert $(\mathrm{He})$ or oxidizing $\left(\mathrm{O}_{2}\right)$ atmosphere. The crystallinity of the films was studied during annealing with in situ X-ray diffraction. 


\section{Experimental}

For the deposition of the tincone films, a custom-built, pump-type deposition tool was utilized. ${ }^{6}$ The reactor walls were kept at a constant temperature of $130{ }^{\circ} \mathrm{C}$ to avoid reactant condensation. The container containing the TDMASn precursor and its delivery line remained at a temperature of $45^{\circ} \mathrm{C}$ and $50^{\circ} \mathrm{C}$ respectively. Argon (99.999\% pure, Air Liquide) was added as a carrier gas to the TDMASn precursor flow in order to increase the exposure of substrate to the precursor. The pressure during TDMASn exposures was $5 \times 10^{-3}$ mbar. The reactant bubblers of EG and GL remained at a temperature of respectively $80^{\circ} \mathrm{C}$ and $60^{\circ} \mathrm{C}$. Similarly as for TDMASn, an additional argon flow was employed during GL exposures. The pressure of EG during the MLD processes was constant at $2 \times 10^{-2}$ mbar. For GL the pressure was $5 \times 10^{-3}$ mbar, including the argon carrier gas flow. In between exposures or in idle operation, the base pressure of the reactor vessel was in the $10^{-6}$ mbar range. Si with native oxide substrates were used for process development, film characterization, and the annealing experiments.

Spectroscopic ellipsometry (SE) was performed with a model M-2000 ellipsometer J.A. Woollam (300 to 1000 $\mathrm{nm})$. SE measurements provide information on the thickness and optical properties of the hybrid films. The included CompleteEASE allowed the analysis of the gathered data. An optical model consisting of a Cauchy dispersion relation was sufficient to accurately describe the SE data. The parameters of the optical model were calibrated with a series of tincone samples with a known thickness from X-ray reflectivity measurements (XRR). The ellipsometer could be mounted on the deposition system. Hence, the growth of the tincone films could be monitored in situ by SE.
The morphology of the tincone films was investigated with scanning electron microscopy (SEM) and atomic force microscopy (AFM). SEM imaging was performed on a Quanta 200F (FEI) microscope using a $10 \mathrm{keV}$ electron beam. AFM images were acquired on a Bruker Dimension Edge microscope. The root mean square (rms) roughness was calculated from the measured $1 \mu \mathrm{m} \times 1 \mu \mathrm{m}$ AFM images.

Infrared spectroscopy was carried out on a Vertex $70 \mathrm{v}$ Fourier-transform infrared (FTIR) spectrometer from Bruker. A globar source (mid IR), DLaTGS detector and KBr beamsplitter were mounted on the optics bench. The spectrometer remained under vacuum during measurements to avoid the appearance of atmospheric absorptions (mainly $\mathrm{CO}_{2}$ and $\mathrm{H}_{2} \mathrm{O}$ ) in the absorption spectra.

X-ray photoelectron spectroscopy (XPS) measurements were executed on a Thermo Scientific Theta Probe system. Aluminium $\mathrm{K} \alpha$ radiation $(\lambda=0.834 \mathrm{~nm})$ was used as an excitation source. Analysis of the gathered data was performed in the CasaXPS software.

$\mathrm{XRR}$ and X-ray diffraction (XRD) measurements were completed on a Bruker D8 Discover diffractometer. For both XRR and XRD, copper $\mathrm{K} \alpha(\lambda=0.154 \mathrm{~nm})$ radiation was utilized. During annealing under reducing ( $\mathrm{He}$ with $5 \% \mathrm{H}_{2}$ ), inert $(\mathrm{He})$ or oxidizing ( $\mathrm{He}$ with $5 \% \mathrm{O}_{2}$ ) atmospheres, in situ XRD was carried out on a homebuilt setup fitted with a position-sensitive detector with a range of $20^{\circ}$ in $2 \theta .^{32}$

\section{Results and discussion}

In the first section, the process development and characterization is discussed. Secondly, the results of the annealing experiments of tincone films in reducing, inert and oxidizing atmospheres are presented. 


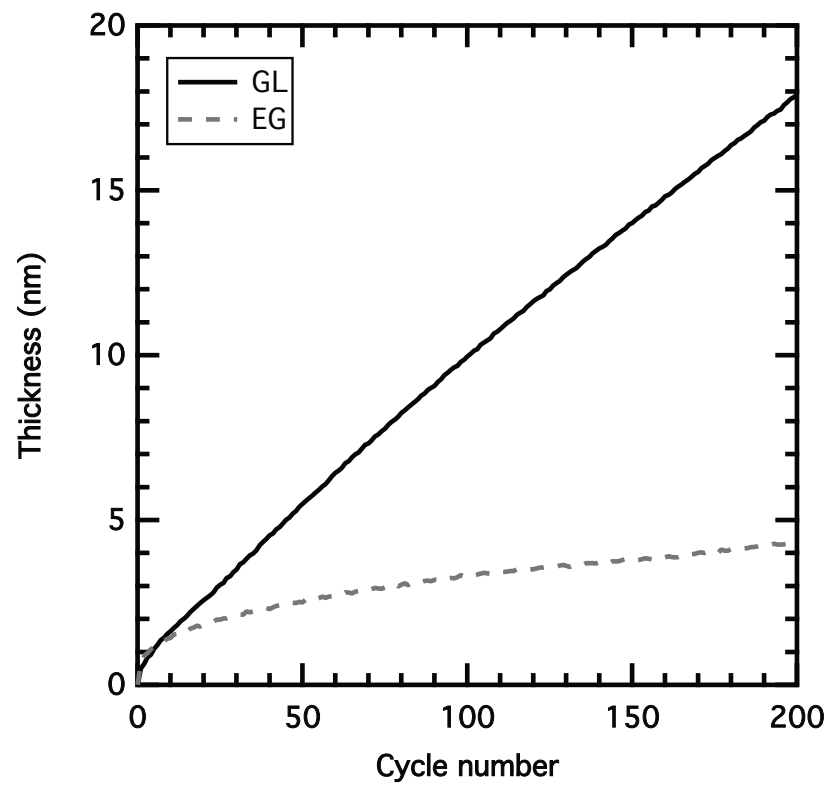

Figure 1: Comparison of the first 200 MLD cycles of the TDMASn/GL and TDMASn/EG processes at a sample temperature of $100{ }^{\circ} \mathrm{C}$.

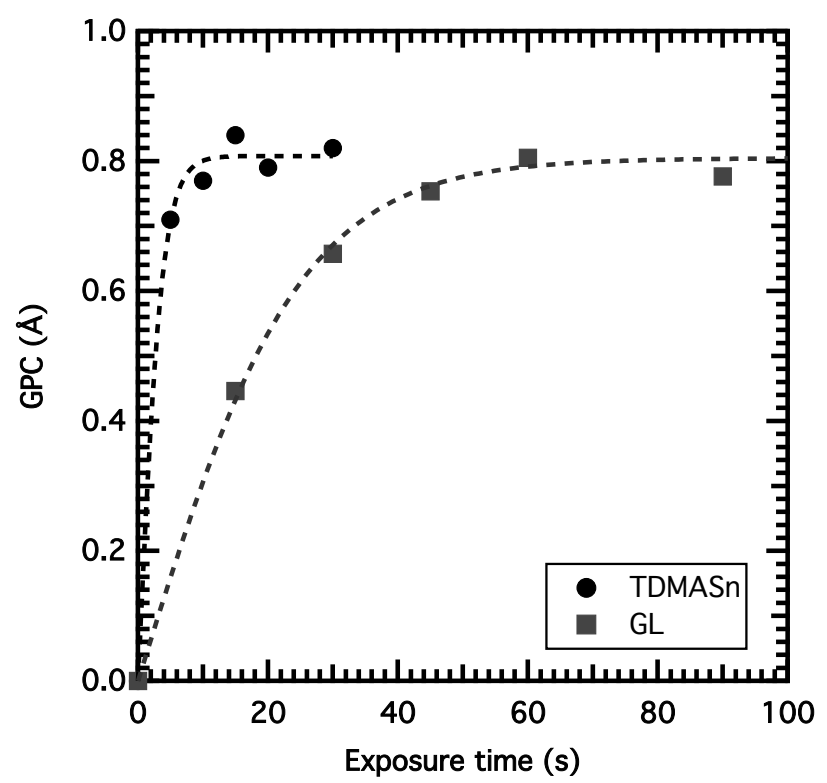

Figure 2: Growth per cycle as a function of precursor and reactant exposure time for the TDMASn/GL MLD process at a sample temperature of $100{ }^{\circ} \mathrm{C}$. Saturation is achieved at exposure times of 20 and 60 seconds for TDMASn and GL respectively. 


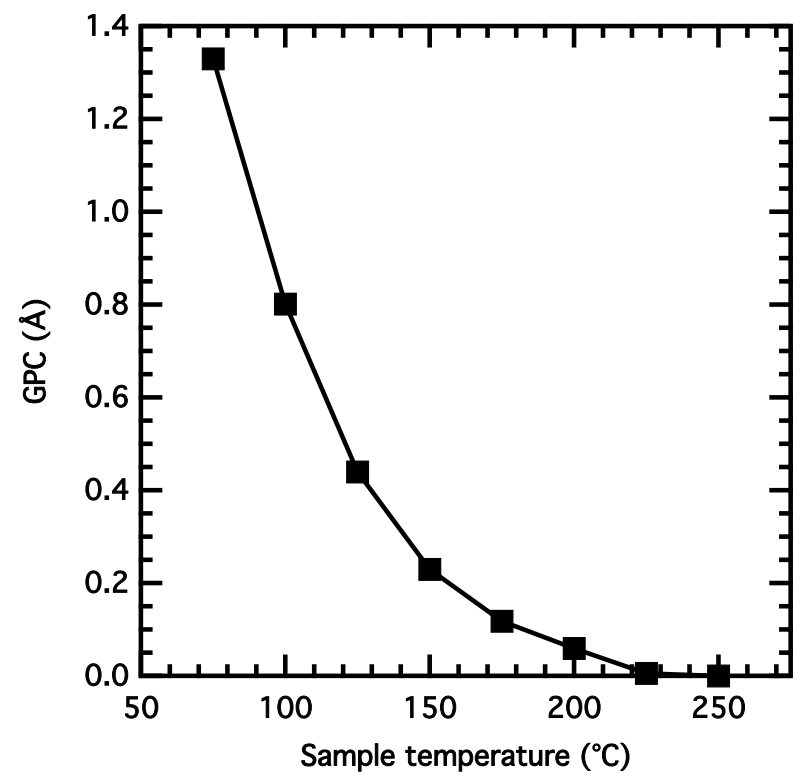

Figure 3: Growth rate versus sample temperature for the TDMASn/GL process. No growth was observed for temperatures above $200^{\circ} \mathrm{C}$.

\section{The tincone MLD process}

\section{Process development}

In order to develop a MLD process for a tin-based, hybrid film, a suitable inorganic precursor and organic reactant need to be selected. As the inorganic precursor, tetrakisdimethylaminotin (TDMASn) is chosen since it is known as an ALD precursor for the deposition of $\mathrm{SnO}_{2} \cdot{ }^{31,33,34}$ As the organic reactant, ethylene glycol (EG) and glycerol (GL) are tested as they have both been implemented successfully in multiple MLD processes. ${ }^{2-6,11}$ By default, the exposure time for TDMASn is $20 \mathrm{~s}$. For EG and GL, the standard pulse times are $30 \mathrm{~s}$ and $60 \mathrm{~s}$ respectively. In situ ellipsometry enables the monitoring of the film growth during the TDMASn/EG and TDMASn/GL MLD processes. After every MLD cycle, the film thickness is measured. The results are presented in figure 1. There is a clear difference in the growth curves for both processes. For the TDMASn/GL process, the growth per cycle (GPC) appears to be stable and the film growth is linear over 200 cycles. The GPC is $0.8 \AA$ at a sample temperature of $100{ }^{\circ} \mathrm{C}$. On the other hand, the GPC of the TDMASn/EG process decreases dramatically over the first 50 cycles after which it becomes stable. At a sample temperature of $100{ }^{\circ} \mathrm{C}$, the GPC for the TDMASn/EG process is $0.1 \AA$ after an initial 50 cycles. The decrease in GPC and slower film growth for an EG-based process in combination with an alkylamine metal precursor has been observed before. ${ }^{6,11}$ The hypothesis is that both $\mathrm{OH}$ end groups of the EG molecules are able to react with surface groups. These double reactions remove active surface sites without adding new groups for the TDMASn molecules to react with. This phenomenon effectively decreases the growth rate of the hybrid film. Previous investigations on alucone films have shown that the inherent flexibility of the organic chains allows these double reactions to proceed, and that these reactions are detrimental for the formation of a smooth and closed film. For the TDMASn/GL process, these possible double reactions do not pose a problem for continued film growth since GL possesses an additional hydroxyl group compared to EG. Due to its low growth rate, the TDMASn/EG process was not 
investigated further in this work.

Saturation curves of the GPC were measured to demonstrate the self-limiting nature of the TDMASn/GL process. The saturation curves were measured at sample temperatures of $100{ }^{\circ} \mathrm{C}$ (figure 2) and $150^{\circ} \mathrm{C}$. At both temperatures, the GPC saturates at TDMASn and GL exposure times of respectively $20 \mathrm{~s}$ and $60 \mathrm{~s}$.

The temperature window for linear film growth with the TDMASn/GL process ranges from 75 to $200{ }^{\circ} \mathrm{C}$. The GPC decreases rapidly with increasing temperature and drops to zero at temperatures above $200{ }^{\circ} \mathrm{C}$. The lower temperature of the temperature window is limited by the temperature of the hot-wall reactor. At the higher end, the sample temperature is not limited due to the high decomposition temperature of TDMASn of $325^{\circ} \mathrm{C} .{ }^{31} \mathrm{An}$ increased TDMASn desorption rate at higher temperatures may explain the decrease in GPC.

\section{Characterization of as deposited films}

The composition, morphology, and other properties of as deposited tincone films were studied ex situ. The tincone films are grown with 300 cycles of the TDMASn/GL process at a substrate temperature of $100^{\circ} \mathrm{C}$ on a silicon substrate with native oxide. All tincone samples used for characterization or annealing experiments were freshly deposited in order to avoid any effect of aging in atmospheric conditions. Although, in the course of a week, no changes in density or composition of the films was observed during aging.

As deposited, the thickness of the films is $28.3 \mathrm{~nm}$ and the density is $2.5 \mathrm{~g} / \mathrm{cm}^{3}$. These values were derived from a simulation of the XRR pattern that is in good agreement with the measurement data (figure 4 ). The surface morphology of the film was verified with AFM. A measurement of an as deposited film is presented in the inset of figure 4 and shows that the films have a low surface rough- ness. SEM confirms this statement on the nanoscopic level as shown in figure 8 .

A working optical model for analyzing the in situ ellipsometry data was constructed for the hybrid tincone films. A model consisting of a simple Cauchy dispersion relation of the type $n(\lambda)=A+B / \lambda^{2}+C / \lambda^{4}$ was sufficient for acquiring a good fit for the SE data. A series of tincone film thickness measurements by XRR were employed to calibrate the parameters of the optical model. This calibration procedure yielded the following parameter values: A $=1.408, \mathrm{~B}=1.725 \times 10^{4} \mathrm{~nm}^{2}$ and $\mathrm{C}=-4.29 \times 10^{8} \mathrm{~nm}^{4}$. At a wavelength of $600 \mathrm{~nm}$, the calculated refractive index is 1.45 in this model.

Fourier transform infrared spectroscopy (FTIR) was performed on as deposited tincone films in order to investigate the chemical composition of the films. The films were measured ex situ. The result of the measurement is shown in figure 5. Two absorption peaks are visible at $2945 \mathrm{~cm}^{-1}$ and $2875 \mathrm{~cm}^{-1}$. These peaks are related to the asymmetrical and symmetrical $\mathrm{CH}_{2}$ stretch modes respectively. The "fingerprint" region of the spectrum reveals the $\mathrm{CH}_{2}$ twisting, and $\mathrm{C}-\mathrm{C}$ and $\mathrm{C}-\mathrm{O}$ stretching modes at wavenumbers of $1252 \mathrm{~cm}^{-1}, 1140 \mathrm{~cm}^{-1}$ and $1075 \mathrm{~cm}^{-1}$ respectively. ${ }^{2}$ At lower wavenumbers several tin-related modes appear in the spectrum. The peaks at $960 \mathrm{~cm}^{-1}$ and $745 \mathrm{~cm}^{-1}$ originate from Sn-O stretching vibrations. The absorption at $870 \mathrm{~cm}^{-1}$ has been previously assigned to vibrations of Sn-OH bonds. ${ }^{35-37}$ The presence of both inorganic and organic components in the spectrum are indicative of the hybrid nature of the film.

X-ray photoelectron spectroscopy (XPS) was also employed to verify the composition of the films, and the oxidation state of Sn inside the films. For determining the atomic composition of the films, first carbon contamination of the surface was removed with two argon sputtering steps. This ensures that the measured carbon signal orig- 


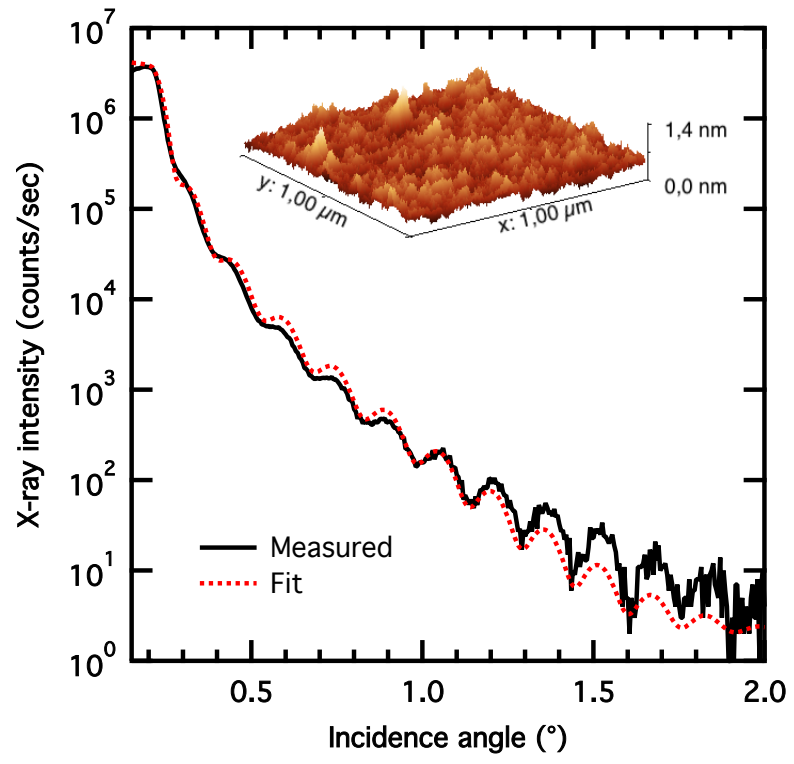

Figure 4: X-ray reflectivity measurement of a tincone film, deposited with 300 TDMASn/GL MLD cycles and the simulated data fit for determining the film thickness and density. The inset shows an $1 \mu \mathrm{m}$ by $1 \mu \mathrm{m}$ AFM image of the same film, illustrating its low rms surface roughness of $0.18 \mathrm{~nm}$.

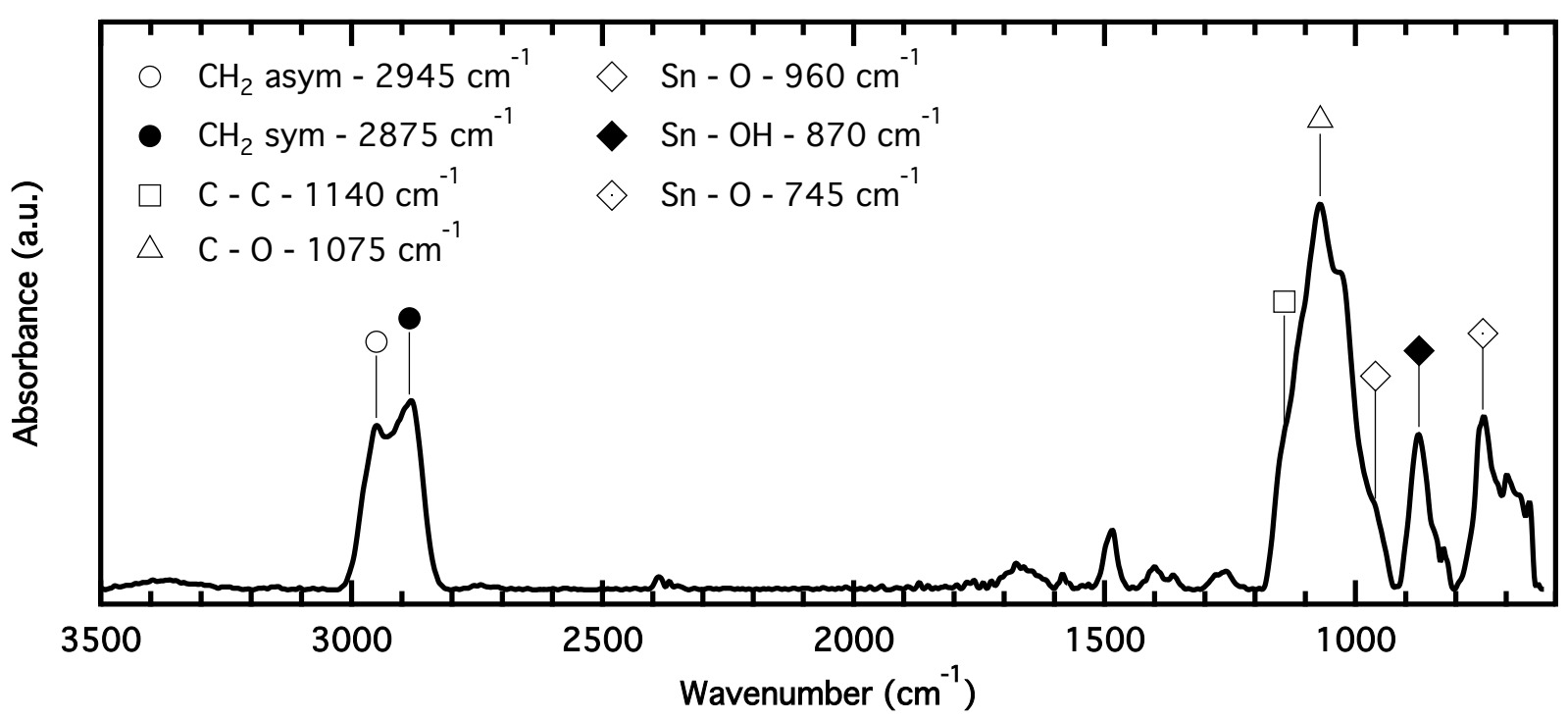

Figure 5: Infrared spectrum of a $28 \mathrm{~nm}$ tincone film, deposited with 300 cycles of the TDMASn/GL MLD process. 
inates from inside the hybrid film, and not from a contaminated surface. The result of the composition analysis can be seen in table 2 . The as deposited film contains about 15 at\% of carbon. Nitrogen contamination from the TDMASn precursor is not observed. The oxidation state of tin inside the hybrid film is determined from the surface XPS spectra, which are calibrated by the carbon 1s line at $284.4 \mathrm{eV}$. In figure 9 , the $3 \mathrm{~d}_{3 / 2}$ and $3 \mathrm{~d}_{5 / 2}$ lines of the spectra can be seen. For the as deposited film, the $3 \mathrm{~d}_{3 / 2}$ and $3 \mathrm{~d}_{5 / 2}$ lines are centered around $494.6 \mathrm{eV}$ and $486.0 \mathrm{eV}$ respectively, which is indicative of the $\mathrm{Sn}^{2+}$ oxidation state. This is unexpected since the oxidation state of tin in the TDMASn precursor is $4+$.

\section{Annealing in reducing, inert and oxidizing atmospheres}

A series of tincone and $\mathrm{SnO}_{2}$ (deposited by ALD) films were annealed in reducing (He with $\left.5 \% \mathrm{H}_{2}\right)$, inert $(\mathrm{He})$ and oxidizing (atmospheres $\mathrm{He}$ with $5 \% \mathrm{O}_{2}$ ) at temperatures up to $700{ }^{\circ} \mathrm{C}$. The films were heated at a ramp rate of $10^{\circ} \mathrm{C} / \mathrm{min}$. After reaching the highest temperature of the treatment, the temperature was kept constant for 10 min before turning off the heating.

The hybrid tincone films were deposited by executing 300 cycles of the TDMASn/GL MLD process at $100^{\circ} \mathrm{C}$ on a silicon substrate with native oxide. The thickness of the films was $28 \mathrm{~nm}$ as deposited. The purely inorganic $\mathrm{SnO}_{2}$ films were deposited by the TDMASn/ $\mathrm{H}_{2} \mathrm{O}$ ALD process. ${ }^{34}$ The substrate temperature during deposition was also $100{ }^{\circ} \mathrm{C}$ and 500 cycles in total were executed. After deposition, the film thickness was measured to be $45 \mathrm{~nm}$ with XRR. The same substrate was used as for the tincone films.

During the annealing treatments, the crystallinity of the films was monitored via in situ X-ray diffraction (XRD). A detection range in $2 \theta$ from $23^{\circ}$ to $42^{\circ}$ was chosen since the most prominent $\mathrm{SnO}$ and $\mathrm{SnO}_{2}$ reflections are expected to appear in this range. After the treatment, the morphology of the films was verified with SEM, and the composition and tin oxidation state with XPS.

An overview of the in situ XRD measurements during the annealing of the tincone films is presented in figure 6 and the results are summarized in table 1. During annealing in $\mathrm{H}_{2}$ and $\mathrm{He}$, a single, strong diffraction peak appears at $36.7^{\circ}$. This peak is assigned to the $\left(\begin{array}{lll}0 & 0 & 2\end{array}\right)$ lattice plane of the tetragonal SnO phase (Romarchite, ICSD card no. 015516). For the anneal in reducing atmosphere, the onset of crystallization is observed at a temperature of $388^{\circ} \mathrm{C}$. At a temperature of $600^{\circ} \mathrm{C}$, the phase disappears again. This is probably due to a further reduction of $\mathrm{SnO}$ into metallic Sn, which then evaporates from the surface. In inert atmosphere, crystallization starts at $410{ }^{\circ} \mathrm{C}$. An anneal in oxidizing atmosphere results in the appearance of a tetragonal $\mathrm{SnO}_{2}$ phase. Two main diffraction peaks are observed at $26.5^{\circ}$ and $37.9^{\circ}$. These peaks correspond to the (1 110$)$ and (2 $\left.\begin{array}{lll}2 & 0\end{array}\right)$ orientations respectively (ICSD card no. 084576). This phase is formed at temperatures above $523^{\circ} \mathrm{C}$.

The heat treatments listed above were repeated on ALD $\mathrm{SnO}_{2}$ films. The results of in situ XRD during annealing are shown in figure 7 and table 1 . In reducing atmosphere, the as deposited amorphous $\mathrm{SnO}_{2}$ film is reduced and crystallizes into a tetragonal $\mathrm{SnO}$ phase (Romarchite, ICSD card no. 015516). Three reflections are observed at $29.5^{\circ}, 32.7^{\circ}$, and $36.7^{\circ}$ that originate from the $\left(\begin{array}{lll}1 & 0 & 1\end{array}\right)$,

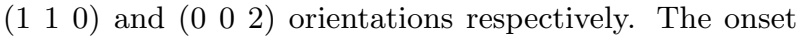
of crystallization is observed at a temperature of $480^{\circ} \mathrm{C}$. Annealing of the ALD $\mathrm{SnO}_{2}$ films in $\mathrm{He}$ and $\mathrm{O}_{2}$ results in the tetragonal $\mathrm{SnO}_{2}$ phase (ICSD card no. 084576). At temperatures above $545^{\circ} \mathrm{C}$, three peaks are observed in the diffractogram. The peaks are located at $26.5^{\circ}, 34.1^{\circ}$, and $38.0^{\circ}$. They are attributed to the $\left(\begin{array}{lll}1 & 1 & 0\end{array}\right),\left(\begin{array}{lll}1 & 0 & 1\end{array}\right)$, and 


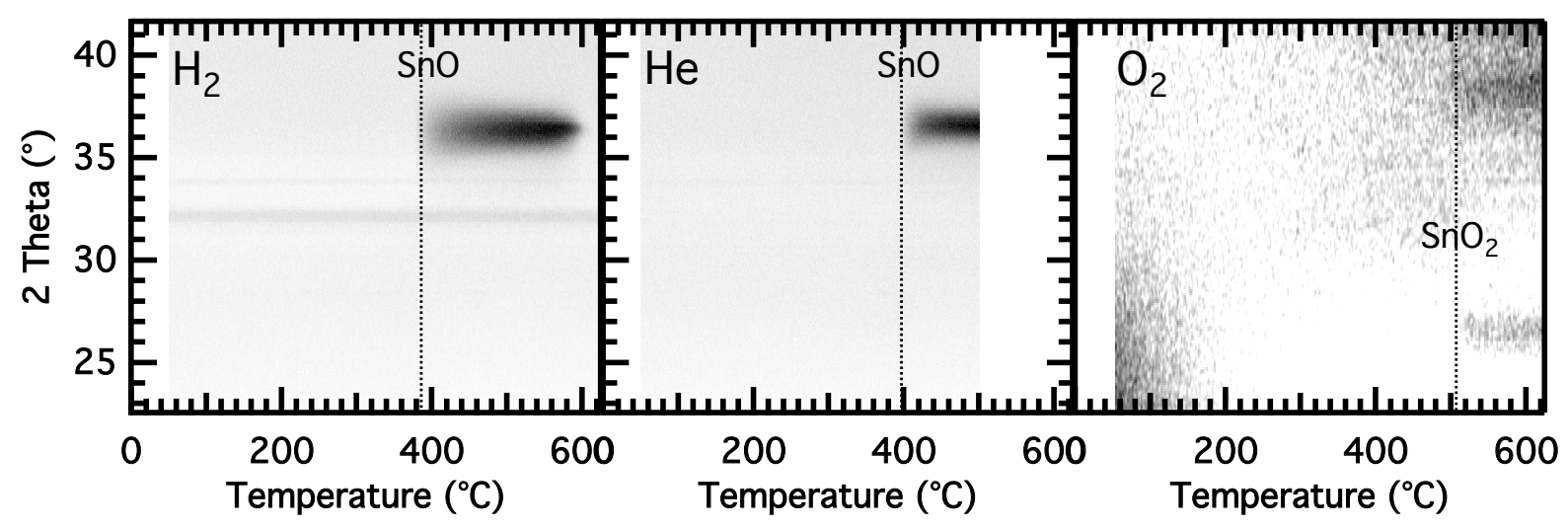

Figure 6: In situ XRD measurements during annealing of tincone films, deposited with $300 \mathrm{MLD}$ cycles, in reducing $\left(\mathrm{H}_{2}\right)$, inert $(\mathrm{He})$, and oxidizing $\left(\mathrm{O}_{2}\right)$ atmospheres. The films were heated at a rate of $10{ }^{\circ} \mathrm{C} / \mathrm{min}$ to $700{ }^{\circ} \mathrm{C}, 500{ }^{\circ} \mathrm{C}$, and $700{ }^{\circ} \mathrm{C}$ in each atmosphere respectively.

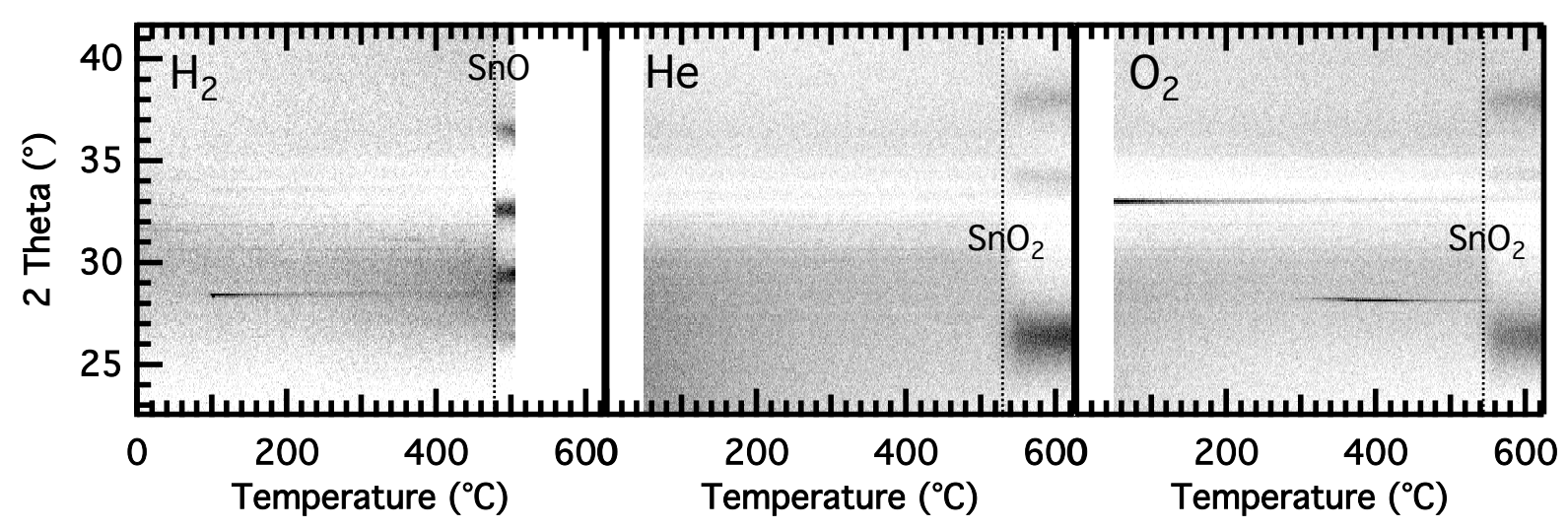

Figure 7: In situ XRD measurements during annealing of reference $\mathrm{SnO}_{2}$ films of $45 \mathrm{~nm}$, deposited by the TDMASn $/ \mathrm{H}_{2} \mathrm{O}$, in reducing $\left(\mathrm{H}_{2}\right)$, inert $(\mathrm{He})$, and oxidizing $\left(\mathrm{O}_{2}\right)$ atmospheres. The films were heated at a rate of $10{ }^{\circ} \mathrm{C} / \min$ to $500{ }^{\circ} \mathrm{C}, 700{ }^{\circ} \mathrm{C}$ and $700{ }^{\circ} \mathrm{C}$ in each atmosphere respectively.

Table 1: Overview table of the formation temperatures (top) and phases (bottom) during annealing of as deposited MLD tincone and ALD $\mathrm{SnO}_{2}$ in reducing $\left(\mathrm{H}_{2}\right)$, inert $(\mathrm{He})$, and oxidizing $\left(\mathrm{O}_{2}\right)$ atmospheres.

\begin{tabular}{|l|c|c|c|}
\hline & $\mathrm{H}_{2}$ & $\mathrm{He}$ & $\mathrm{O}_{2}$ \\
\hline Tincone & $388^{\circ} \mathrm{C}$ & $410{ }^{\circ} \mathrm{C}$ & $523^{\circ} \mathrm{C}$ \\
& $\mathrm{SnO}$ (tetragonal) & $\mathrm{SnO}$ (tetragonal) & $\mathrm{SnO}_{2}$ (tetragonal) \\
\hline \multirow{2}{*}{$\mathrm{ALD} \mathrm{SnO}_{2}$} & $480^{\circ} \mathrm{C}$ & $545^{\circ} \mathrm{C}$ & $545^{\circ} \mathrm{C}$ \\
& $\mathrm{SnO}$ (tetragonal) & $\mathrm{SnO}_{2}$ (tetragonal) & $\mathrm{SnO}_{2}$ (tetragonal) \\
\hline
\end{tabular}


(2 $\left.\begin{array}{lll}2 & 0\end{array}\right)$ lattice planes respectively.

After annealing, the morphology of the films is investigated via SEM imaging. Representative images of the films are shown in figure 8. The samples annealed in hydrogen and helium display a rough surface and a grainy structure that was formed during crystallization. Small agglomerated islands are visible in the samples annealed in oxygen.

The tin oxidation state and composition of the annealed films were determined with XPS. The $3 \mathrm{~d}_{3 / 2}$ and $3 \mathrm{~d}_{5 / 2}$ lines of the XPS spectra are presented in figure 9. The position of these lines with respect to a calibrated carbon 1s line provides information about the oxidation state of tin inside the films. For the samples annealed in $\mathrm{H}_{2}$ and $\mathrm{He}$, the $3 \mathrm{~d}_{3 / 2}$ and $3 \mathrm{~d}_{5 / 2}$ lines are centered around $494.6 \mathrm{eV}$ and $486.0 \mathrm{eV}$ respectively. This suggests a $2+$ oxidation state of tin for these samples. The XPS spectrum of the samples annealed in oxygen shows that the $3 \mathrm{~d}_{3 / 2}$ and $3 \mathrm{~d}_{5 / 2}$ lines are located at $495.2 \mathrm{eV}$ and $486.7 \mathrm{eV}$ and implies a $\mathrm{Sn}^{4+}$ state. This observation is in line with the tin oxide phases observed in in situ XRD. The composition analysis with XPS of the annealed films is presented in table 2. The heat treatment significantly reduces the carbon content of the films. The measured stoichiometry of the films also coincides with the observed phases.

Comparison of the in situ XRD results of the tincone and ALD $\mathrm{SnO}_{2}$ films show several notable differences. The first main difference is crystallization behaviour of the films in inert atmosphere. The tincone films crystallize into the $\mathrm{SnO}$ phase, while the $\mathrm{ALD} \mathrm{SnO}_{2}$ crystallize, unsurprisingly, into the $\mathrm{SnO}_{2}$. This can be explained by considering the starting oxidation state of tin in the as deposited films. For the tincone films tin can be found in the $\mathrm{Sn}^{2+}$ state as opposed to the ALD films where tin is in the $\mathrm{Sn}^{4+}$ state. Secondly, the $\mathrm{SnO}$ phase formation in the tincone films shows only a single, strong reflection while the $\mathrm{SnO}$ phase in the ALD films shows multiple. Hence, the tincone $\mathrm{SnO}$ phase is preferentially oriented towards the $\left(\begin{array}{lll}0 & 0 & 2\end{array}\right)$ lattice plane. A final important difference is the crystallization temperature of the $\mathrm{SnO}$ phase. This temperature is generally lower for the tincone samples, as is illustrated in figure 10. For films annealed in hydrogen, the onset temperature for crystallization is approximately $90^{\circ} \mathrm{C}$ lower for the tincone films as compared to the ALD films. The crystallization temperature for tincone annealed in $\mathrm{He}$ is about $70^{\circ} \mathrm{C}$ lower with respect to the $\mathrm{H}_{2}$-annealed ALD films. The $\mathrm{SnO}_{2}$ phase crystallization temperature is, however, similar for both tincone and ALD $\mathrm{SnO}_{2}$ films.

\section{Conclusions}

In this work, the growth and properties of hybrid, tinbased tincone films, deposited by molecular layer deposition, was investigated. For the deposition process, tetrakisdimethylaminotin (TDMASn) was employed as the metallorganic precursor for tin in combination with ethylene glycol (EG) and glycerol (GL) as the organic reactants. Steady-state growth was achieved for both processes. The growth per cycle (GPC) for the TDMASn/EG process was, however, considerably lower $\left(0.1 \AA\right.$ at $\left.100^{\circ} \mathrm{C}\right)$ than for the TDMASn/GL process $\left(0.8 \AA\right.$ at $\left.100{ }^{\circ} \mathrm{C}\right)$. For this reason, only the TDMASn/GL process was studied further in this work. The TDMASn/GL process displayed linear and saturated growth in a broad temperature range. With increasing temperature, the growth per cycle decreased rapidly from $1.3 \AA$ at $75^{\circ} \mathrm{C}$ to less than $0.1 \AA$ at $200^{\circ} \mathrm{C}$. No growth was observed at higher temperatures.

The refractive index and density of the as deposited films were determined to be 1.45 at $600 \mathrm{~nm}$ and $2.5 \mathrm{~g} / \mathrm{cm}^{3}$ with $\mathrm{SE}$ and XRR respectively. The morphology of the films 


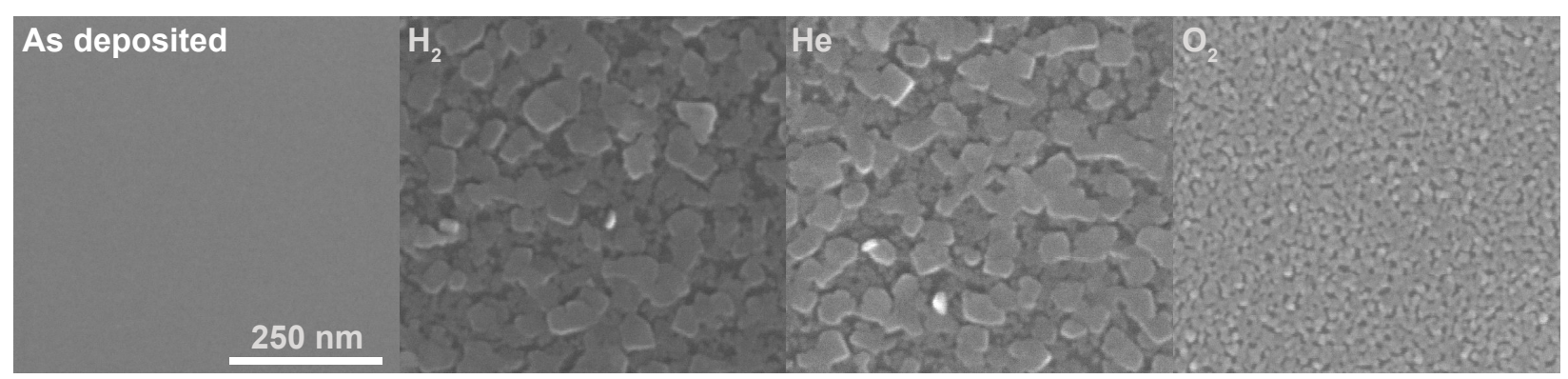

Figure 8: SEM images of the as deposited and annealed tincone samples. The samples annealed in $\mathrm{H}_{2}$ and $\mathrm{He}_{\mathrm{e}}$ were quenched at $500^{\circ} \mathrm{C}$. The samples annealed in $\mathrm{O}_{2}$ were quenched at 700

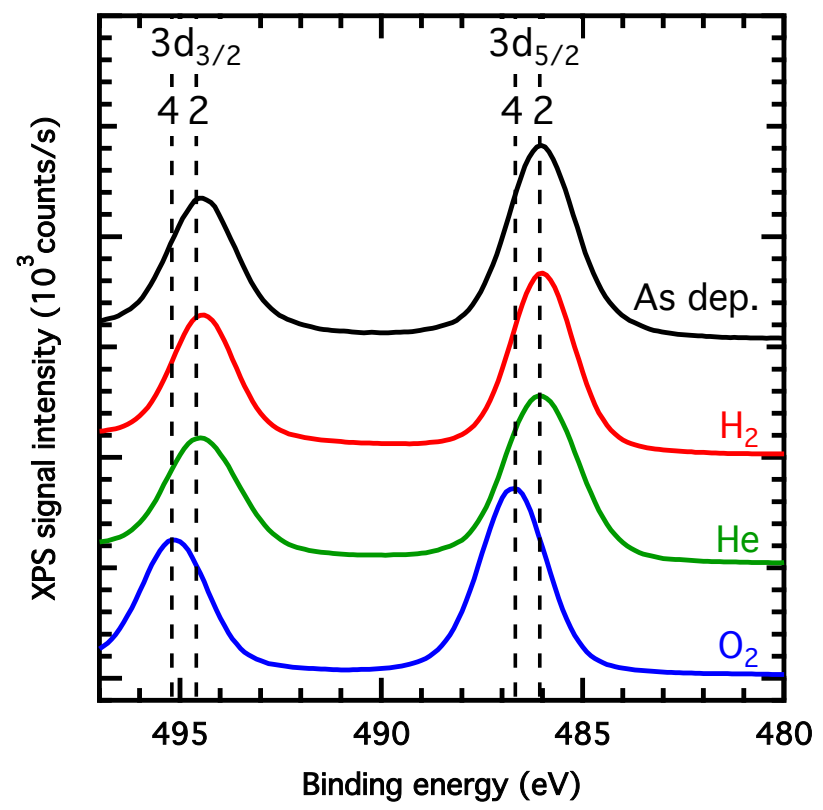

Figure 9: Difference in tin oxidation state between the different tincone samples, as measured by XPS. The carbon 1s line was calibrated at $284.8 \mathrm{eV}$. The samples annealed in $\mathrm{H}_{2}$ and He were quenched at $500{ }^{\circ} \mathrm{C}$. 
Table 2: Summary of the characterization results of the as deposited and annealed tincone films. The samples annealed in $\mathrm{H}_{2}$ and $\mathrm{He}$ were quenched at $500{ }^{\circ} \mathrm{C}$.

\begin{tabular}{|l|c|ccc|}
\hline & Crystallinity & \multicolumn{4}{|c|}{ Composition (at\%) } \\
& & $\mathrm{C}$ & $\mathrm{Sn}$ & $\mathrm{O}$ \\
\hline As deposited & Amorphous & 15 & 52 & 33 \\
Anneal in $\mathrm{He}$ to $500^{\circ} \mathrm{C}$ & $\mathrm{SnO}$ & 5 & 52 & 43 \\
Anneal in $\mathrm{H}_{2}$ to $500^{\circ} \mathrm{C}$ & $\mathrm{SnO}$ & 7 & 53 & 40 \\
Anneal in $\mathrm{O}_{2}$ to $700^{\circ} \mathrm{C}$ & $\mathrm{SnO}_{2}$ & 1 & 38 & 61 \\
\hline
\end{tabular}

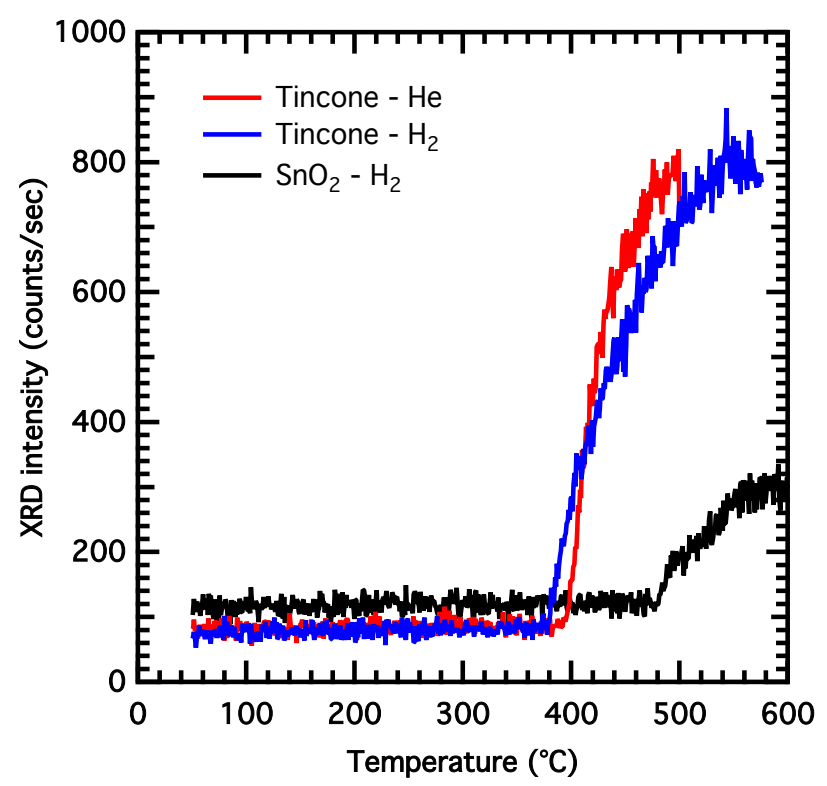

Figure 10: XRD intensity of the $(200) \mathrm{SnO}$ reflection as a function of temperature. The $(200)$ reflection corresponds to a $2 \theta$ value of 36.7 degrees.

was shown to be smooth with a low surface roughness with SEM and AFM. The hybrid nature of the as deposited films was confirmed with both FTIR and XPS. Both spectra displayed both organic and inorganic components. XPS revealed the oxidation state of tin in the as deposited films to be $2+$.

As deposited tincone films were annealed in reducing $\left(\mathrm{H}_{2}\right)$, inert $(\mathrm{He})$ or oxidizing $\left(\mathrm{O}_{2}\right)$ atmospheres. The crystallization of the films was studied in situ with X-ray diffraction (XRD). Ex situ the annealed films were studied with SEM and XPS. For comparison purposes, tin oxide films deposited via ALD were subjected to identical annealing treatments. XRD revealed that both the films annealed in reducing or inert atmospheres crystallized to a tetragonal tin monoxide phase at $388^{\circ} \mathrm{C}$ and $410{ }^{\circ} \mathrm{C}$ respectively. This was supported by XPS measurements that indicated a $2+$ oxidation state for tin. In comparison, the ALD tin oxide films crystallized into $\mathrm{SnO}$ only in reducing atmosphere and at a higher temperature of $480^{\circ} \mathrm{C}$. The tincone films that crystallized into $\mathrm{SnO}$ during annealing displayed a grainy and rough structure in SEM, and a significantly reduced carbon content in XPS. The tincone films annealed in oxygen crystallized into a tetragonal $\mathrm{SnO}_{2}$ phase at $523^{\circ} \mathrm{C}$. This observation was also supported by a tin oxidation state of $4+$ seen in XPS. Similar crystallization behaviour was observed for 
the reference ALD tin oxide films that were annealed in inert or oxidizing atmosphere. Tincone films annealed in oxygen showed small agglomerated islands in SEM. XPS indicated that all carbon content was removed from these films during the annealing treatment.

This work adds a new hybrid "metalcone" to the catalog of materials that can be deposited via MLD. The results from the annealing experiments may prove to be interesting for the semiconductor industry since $\mathrm{SnO}$ is one of the few metal oxides known as a p-type semiconductor material.

\section{Acknowledgement}

The authors are grateful to FWO Vlaanderen for providing Kevin Van de Kerckhove with financial support through the mandate of Aspirant. J.D. acknowledges the FWO for a post-doc grant. They also acknowledge the IWT Vlaanderen (IWT-SBO SOSLion project), BOFUGent (GOA 01G01513), and the Hercules foundation for providing funding for this work. They thank Karl Opsomer and Matthias Minjauw for the XPS measurements, Tareq Ahmad for AFM, and Olivier Janssens for SEM work.

\section{References}

(1) George, S. M. Chemical Reviews 2010, 110, 111131.

(2) Bertrand, J. A.; Dameron, A. A.; Seghete, D.; Burton, B. B.; Davidson, S. D.; Cavanagh, A. S.; George, S. M. Chemistry of Materials 2008, 20, $3315-3326$.

(3) George, S. M.; Lee, B. H.; Yoon, B.; Abdulagatov, A. I.; Hall, R. A. Journal of Nanoscience and Nanotechnology 2011, 11, 7948-7955.
(4) Van de Kerckhove, K.; Barr, M. K. S.; Santinacci, L.; Vereecken, P. M.; Dendooven, J.; Detavernier, C. Dalton Transactions 2018,

(5) Abdulagatov, A. I.; Hall, R. A.; Sutherland, J. L.; Lee, B. H.; Cavanagh, A. S.; George, S. M. Chemistry of Materials 2012, 24, 2854-2863.

(6) Van de Kerckhove, K.; Mattelaer, F.; Deduytsche, D.; Vereecken, P. M.; Dendooven, J.; Detavernier, C. Dalton Transactions 2016, 45, 11761184.

(7) Yoon, B.; O'Patchen, J. L.; Seghete, D.; Cavanagh, A. S.; George, S. M. Chemical Vapor Deposition 2009, 15, 112-121.

(8) Peng, Q.; Gong, B.; VanGundy, R. M.; Parsons, G. N. Chemistry of Materials 2009, 21, 820830.

(9) Lee, B. H.; Anderson, V. R.; George, S. M. Chemical Vapor Deposition 2013, 19, 204-212.

(10) Lee, B. H.; Anderson, V. R.; George, S. M. ACS Applied Materials $\&$ Interfaces 2014, 6, 16880-16887.

(11) Van de Kerckhove, K.; Mattelaer, F.; Dendooven, J.; Detavernier, C. Dalton Transactions 2017, 192, $1126-20$

(12) Lee, B. H.; Lee, K. H.; Im, S.; Sung, M. M. Organic Electronics 2008, 9, 1146-1153.

(13) Lee, B. H.; Yoon, B.; Anderson, V. R.; George, S. M. The Journal of Physical Chemistry C 2012, 116, 3250-3257.

(14) Liang, X.; Yu, M.; Li, J.; Jiang, Y.-B.; Weimer, A. W. Chemical Communications 2009, 7140-7142. 
(15) Liang, X.; Evanko, B. W.; Izar, A.; King, D. M.; Jiang, Y.-B.; Weimer, A. W. Microporous and Mesoporous Materials 2013, 168, 178-182.

(16) DuMont, J. W.; George, S. M. Journal of Physical Chemistry C 2015, 119, 14603-14612.

(17) Abdulagatov, A. I.; Terauds, K. E.; Travis, J. J.; Cavanagh, A. S.; Raj, R.; George, S. M. Journal of Physical Chemistry C 2013, 117, 17442-17450.

(18) Rumyantseva, M. N.; Safonova, O. V.; Boulova, M. N.; Ryabova, L. I.; Gas'kov, A. M. Russian Chemical Bulletin 2003, 52, 1217-1238.

(19) Arafat, M. M.; Dinan, B.; Akbar, S. A.; Haseeb, A. S. M. A. Sensors 2012, 12, 7207-7258.

(20) Choi, G.; Satyanarayana, L.; Park, J. Applied Surface Science 2006, 252, 7878-7883.

(21) Tan, S.-S.; Kee, Y.-Y.; Wong, H.-Y.; Tou, T.-Y. Surface $E$ Coatings Technology 2013, 231, 98-101.

(22) Görrn, P.; Ghaffari, F.; Riedl, T.; Kowalsky, W. Solid State Electronics 2009, 53, 329-331.

(23) Chou, L.-W.; Lin, Y.-Y.; Wu, A. T. Applied Surface Science 2013, 277, 30-34.

(24) Kang, B.; Tan, L. W.; Silva, S. R. P. Applied Physics Letters 2008, 93, 133302-3.

(25) Gordon, R. Journal of Non-Crystalline Solids 1997, 218, 81-91.

(26) Idota, Y. Science 1997, 276, 1395-1397.

(27) Mohamedi, M.; Lee, S. J.; Takahashi, D.; Nishizawa, M.; Itoh, T.; Uchida, I. Electrochimica Acta 2001, 46, 1161-1168.
(28) Meduri, P.; Pendyala, C.; Kumar, V.; Sumanasekera, G. U.; Sunkara, M. K. Nano Letters 2009, 9, $612-616$.

(29) Caraveo-Frescas, J. A.; Nayak, P. K.; AlJawhari, H. A.; Granato, D. B.; Schwingenschlögl, U.; Alshareef, H. N. ACS Nano 2013, \%, $5160-5167$.

(30) Han, J. H.; Chung, Y. J.; Park, B. K.; Kim, S. K.; Kim, H.-S.; Kim, C. G.; Chung, T.-M. Chemistry of Materials 2014, 26, 6088-6091.

(31) Nazarov, D. V.; Bobrysheva, N. P.; Osmolovskaya, O. M.; Osmolovsky, M. G.; Smirnov, V. M. Reviews on Advanced Materials Science 2015, 40, 262-275.

(32) Knaepen, W.; Detavernier, C.; Van Meirhaeghe, R. L.; Jordan Sweet, J.; Lavoie, C. Thin Solid Films 2008, 516, 4946-4952.

(33) Elam, J. W.; Baker, D. A.; Hryn, A. J.; Martinson, A. B. F.; Pellin, M. J.; Hupp, J. T. Journal of Vacuum Science \& Technology A 2008, 26, 244-252.

(34) Mullings, M. N.; Hägglund, C.; Bent, S. F. Journal of Vacuum Science \& Technology A 2013, 31, 061503-9.

(35) Chaisitsak, S. Sensors 2011, 11, 7127-7140.

(36) Van Tran, T.; Turrell, S.; Eddafi, M.; Capoen, B.; Bouazaoui, M.; Roussel, P.; Berneschi, S.; Righini, G.; Ferrari, M.; Bhaktha, S. N. B.; Cristini, O.; Kinowski, C. Journal of Molecular Structure 2010, 976, 314-319.

(37) Khan, A. F.; Mehmood, M.; Aslam, M.; Ashraf, M. Applied Surface Science 2010, 256, 2252-2258. 
Graphical TOC Entry 